\title{
Perforin and hematological cancer
}

\section{Dimas Tadeu Covas}

Regional Blood Center of Ribeirão Preto, Faculdade de Medicina de Ribeirão Preto, Universidade de São Paulo FMRP-USP, Ribeirão Preto, SP, Brazil
Conflict-of-interest disclosure:

The authors declare no competing financial interest

Submitted: 8/9/2011

Accepted: 8/10/2011

\section{Corresponding author:}

Dimas Tadeu Covas

Regional Blood Center of Ribeirão Preto,

Faculdade de Medicina de Ribeirão Preto Universidade de São Paulo

Rua Tenente Catão Roxo, 250

Bairro Monte Alegre

14051-140 - Ribeirão Preto, SP, Brazil

dimas@fmrp.usp.br

www.rbhh.org or www.scielo.br/rbhh

DOI: 10.5581/1516-8484.20110070
Perforin (PRF) is a soluble cytotoxic pore-forming glycoprotein that is a crucial component of the cocktail of cytotoxic granules harbored by cytotoxic $\mathrm{T}$ lymphocytes (CTL) and natural killer cells (NK), collectively known as cytotoxic lymphocytes (CLs). CLs are able to detect virus-infected or transformed cells and destroy them through perforindependent mechanisms and death receptor-dependent pathways. The cell lytic pathway also involves the interaction of perforin and other granule toxins, particularly those of the granzyme family of cytotoxins. ${ }^{(1)}$

Perforin is encoded by the PRF1 gene located in chromosome 10q22 in humans. PRF 1 gene is approximately $6 \mathrm{~kb}$ long and is composed of three exons and a promoter region of $1409 \mathrm{bp} .^{(2)}$

Deficiency of PRF results in severe immunodeficiency in both mice and humans. PRFdeficient mice are pathologically susceptible to many viruses and develop B cell lymphomas. ${ }^{(3)}$ Deficiency of PRF in human infants leads to an aggressive immunoregulatory disorder called familial hemophagocytic lymphohistiocytosis (FHL) that appears within the first few months of life. FHL is fatal unless treated with cytotoxic drugs followed by bone marrow transplantation. Partial deficiency of PRF leads to a late-onset form of FHL characterized by the appearance of various forms of hematological malignancies, including $\mathrm{B}$ and T-cell lymphomas, and acute and chronic leukemias. ${ }^{(1)}$ These data strongly suggest that deficiency of CL function due to PRF deficiency has a critical role in the increased incidence of cancer.

Sixteen allelic variants of the PRF1 gene, which result in perforin deficiency, have been described (OMIN \# 170280). These variants are determined by point mutations and base deletions in the coding region of the PRF1 gene. In homozygosis these variants result in reduced expression or in the synthesis of a truncated protein. Three variants (W374T, $\mathrm{N} 252 \mathrm{~S}$ and $\mathrm{A91V}$ ) are clearly linked to the development of hematologic cancers.

The A91V allele is the most prevalent variant in the Caucasian population with a reported frequency of between 3 and 17\%. The A91V frequency is very low in AfricanAmericans and there are no reported cases of this polymorphism in Japanese subjects. The A91V polymorphism has also been proposed to predispose patients to B and T-cell lymphoma, acute lymphoblastic leukemia, anaplastic large cell lymphoma, and Dianzani autoimmune lymphoproliferative disease. In a large epidemiological study, an increased incidence of the A91V mutation was found in BCR-ABL positive ALL patients indicating the necessity to investigate the effect of the presence of the A91V allele in a large cohort of cancer patients.

The importance of the association of PRF function and the predisposition to hematological cancer was recently emphasized by Chia et al. who conducted a study in a cohort of patients with atypical or delayed FHL type $2{ }^{(4)}$ The authors found a frequency of hematological cancer of over 100 times higher than that reported in the general population and argue in favor of the important role of PRF in the immune surveillance of cancer. 
PRF deficiency occurs not only with allelic variants characterized by mutations in the coding region of the gene. McIlroy et al. reported that the occurrence of a $\mathrm{C} / \mathrm{T}$ polymorphism at position -398 of the proximal promoter region of the PRF1 gene was associated with decreased quantities of PRF in CTLs in HIV infected patients. A decrease of about $50 \%$ of control PRF levels was observed in heterozygous patients but no patients homozygous for $-398 \mathrm{~T} / \mathrm{T}$ mutations were studied. ${ }^{(5)}$

In this issue of the Revista Brasileira de Hematologia e Hemoterapia, Garcia et al. ${ }^{(6)}$ present an analysis of the frequency of the C398T polymorphism in a cohort of 62 patients with hematological cancers that had no allelic disequilibrium when compared to control populations matched by inferred ascendency. However, they describe an excess of the C398T polymorphism in the patients taken as whole group compared with the controls. This discrepancy could be attributed to the small number of patients studied or to the criteria used to define the control population. It is worth mentioning that all patients, except for one, were heterozygous (C398T). The only homozygous patient has myelodysplastic syndrome, but unfortunately the corresponding clinical and epidemiological data were not included in the paper.

Overall, the paper raises a number of important questions related to the role of PRF in hematological cancer and some points should be addressed in future studies:

1. Is the level of PRF reduced in the cancer patients studied as observed in HIV infected patients?
2. Is the CTL response of the lymphocytes of patients with the allelic variants normal when compared to patients with wild type and normal individuals?

3. What is the prevalence of the coding allelic variants in this group of patients?

To clarify these important points it is necessary to increase the population enrolled and perform the entire PRF1 gene sequencing of patients and matched controls. A multicenter study would be welcome.

\section{References}

1. Brennan AJ, Chia J, Trapani JA, Voskoboinik I. Perforin deficiency and susceptibility to cancer. Cell Death Differ. 2010;17(4):607-15.

2. Lichtenheld MG, Podack ER. Structure of the human perforin gene. A simple gene organization with interesting potential regulatory sequences. J Immunol. 1989;143(12):4267-74.

3. Kagi D, Ledermann B, Burki K, Seiler P, Odermatt B, Olsen KJ, et al. Cytotoxicity mediated by $\mathrm{T}$ cells and natural killer cells is greatly impaired in perforin-deficient mice. Nature. 1994;369(6475):31-7.

4. Chia J, Yeo KP, Whisstock JC, Dunstone MA, Trapani JA, Voskoboinik I. Temperature sensitivity of human perforin mutants unmasks subtotal loss of cytotoxicity, delayed FHL, and a predisposition to cancer. Proc Natl Acad Sci U S A. 2009;106(24):9809-14.

5. Mcllroy D, Meyer L, Dudoit Y, Samri A, Delfraissy JF, Autran B, et al. Polymorphism in the proximal promoter region of the perforin gene and its impact on the course of HIV infection. Int $\mathrm{J}$ Immunogenet. 2006;33(2):73-9.

6. Garcia FB, dos Reis RK, da Silva LE, Moraes-Souza H. Analysis of the $398 \mathrm{C} / \mathrm{T}$ polymorphism in the perforin gene in oncohematological patients Rev Bras Hematol Hemoter. 2011;33(4):274-6. 